\title{
High spatial resolution climatology of drought events for Spain: 1961-2014
}

High spatial resolution climatology of drought events for Spain

Fernando Domínguez-Castro ${ }^{1,}$, Sergio M. Vicente-Serrano ${ }^{1}$, Miquel Tomás-Burguera ${ }^{2}$, Marina Peña-Gallardo ${ }^{1}$, Santiago Beguería ${ }^{2}$, Ahmed El Kenawy ${ }^{1,3,4}$, Yolanda Luna ${ }^{5}$, Ana Morata $^{5}$

1. Instituto Pirenaico de Ecología, Consejo Superior de Investigaciones Científicas (IPECSIC), Campus de Aula Dei, P.O. Box 13034, E-50059, Zaragoza, Spain (*Contact: f.dominguez@ipe.csic.es)

2. Estación Experimental de Aula Dei, Consejo Superior de Investigaciones Científicas (EEAD-CSIC), Campus de Aula Dei, Zaragoza, Spain

3. Department of Geography, Mansoura University, Mansoura, Egypt

4. Department of Geography, Sultan Qaboos University, Alkhoud, Muscat, Oman

5. Agencia Estatal de Meteorología (AEMET), Madrid, Spain

\begin{abstract}
This study characterizes the climatology of drought events over the mainland Spain and the Balearic Islands using high-resolution $\left(1.21 \mathrm{~km}^{2}\right)$ meteorological data from 1961 to 2014. The climatology of drought was assessed based on two widely-recognized drought indices: the Standardized Precipitation Index (SPI) and the Standardized PrecipitationEvapotranspiration Index (SPEI), considering four different timescales (1-, 3-, 6- and 12months). Drought events were simply defined as sequences of months with negative values of the indices. We analyzed the spatial and temporal variability of the frequency, duration and magnitude of the drought events. In general, the frequency of drought events is higher in the northern than in the southern regions. Conversely, the average duration and magnitude of the drought events in central and southwestern regions duplicate those recorded in northern areas. Although drought characteristics exhibit a general north-south gradient irrespective of the drought timescale and the drought index analyzed, we found important spatial differences in terms of both drought duration and severity. As opposed to the SPI, the SPEI shows, on average, higher drought durations and magnitudes at 1-, 3- and 6-months timescales. Albeit of the absence of significant temporal changes in drought duration or magnitude at the regional scale, a non-significant tendency toward higher drought duration and magnitude is observed over the majority of Spain. Our result provide valuable guidance to stakeholders and decision-makers on detecting, monitoring and adapting to drought impacts at local, regional and national scale in Spain.
\end{abstract}

This article has been accepted for publication and undergone full peer review but has not been through the copyediting, typesetting, pagination and proofreading process, which may lead to differences between this version and the Version of Record. Please cite this article as doi: 10.1002/joc.6126 
Keywords: Drought, Spain, SPI, SPEI, Climatology

\section{Introduction}

Drought is one of the main climatic risks affecting Spain, with drastic impacts on both natural and human environments (Vicente-Serrano et al., 2014a). Several historical drought episodes in Spain have already been identified either in documentary sources (e.g. Vicente-Serrano and Cuadrat, 2007; Domínguez-Castro et al., 2008, 2014) or from dendrochronological records (e.g. Tejedor et al., 2016, 2017). The available long instrumental data covering the entire 20th century suggests an increase in the frequency and severity of drought episodes across Iberia (Vicente-Serrano, 2006a and 2013). In Spain, droughts have strong impacts on crop yields (Vicente-Serrano et al., 2006; Páscoa et al., 2017), forest fires (Pausas, 2004; Gouveia et al., 2012; Turco et al., 2017), forest decay and mortality (Camarero et al., 2015a), surface water resources (Lorenzo-Lacruz et al., 2013) and groundwater (Lorenzo-Lacruz et al., 2017). It is important to note that the impacts of drought on different environmental and societal sectors are broadly determined by the timescale at which drought is assessed. In specific, the impacts of drought on agriculture and vegetation activity are mainly related with 3- and 6-months timescales (Pacoa et al., 2017; Gouviera et al., 2017; Peña-Gallardo et al., 2019). On the other hand, the hydrological impacts of drought depend on the characteristics of the basins. In particular, small basins with permeability rock substrates respond quickly to drought at short times scales (e.g. 2-3 months), while basins with a dominant role of groundwater reserves respond to longer timescales (i.e. more than 10 months) (LorenzoLacruz et al., 2013). In the same context, the response of the forests to drought is better assessed at short timescales (i.e. 1-3 months) in humid-temperate hardwood forests, whereas they respond to medium-to-long timescale (more than 4 months) in warm-dry conifer forests (Peña-Gallardo et al., 2018). 
Drought has a remarkable social concern in Spain, due to its adverse impacts, particularly in local rural communities. The impacts of drought on crop failure, urban settlements, urban water resources, and even ecology have already been documented in earlier works (e.g. Pausas and Fernández-Muñoz, 2012; Camarero et al., 2015b).

Several studies analyzed droughts in Spain from a climatic perspective, focusing mainly on the complex atmospheric mechanisms controlling drought severity (e.g. Vicente-Serrano and López-Moreno, 2006; García-Herrera et al., 2007; Trigo et al., 2013) and their spatiotemporal patterns. A representative example is Vicente-Serrano (2006 and 2013) who analyzed the variability of droughts in the Iberian Peninsula since the beginning of the $20^{\text {th }}$ century using the Standardized Precipitation Index (SPI), suggesting strong spatial variability of drought. Previous works show strong spatial differences in the temporal evolution of drought indices over Spain, concluding that drought occurrence is not simultaneous among all regions. However, the regions whose climate is largely controlled by different atmospheric circulation mechanisms are found homogeneous in terms of drought variability (see, for example, Rodríguez-Puebla et al., 1998; Serrano et al., 1999; Trigo et al., 2004; Martín-Vide and López-Bustins, 2006; Lorenzo-Lacruz and Moran Tejeda, 2016).

The climate of Spain is extremely complex, with strong spatial variability of temperature, precipitation and aridity conditions (Martín-Vide and Olcina, 2001); it also shows noticeable recent temporal trends (Vicente-Serrano et al., 2017a). For example, while northern Spain is characterized by its humid oceanic conditions, central Spain shows strong continental features, given the distribution of mountain chains (e.g. the Iberian System, Sierra Nevada). On the other hand, northeastern and southeastern Spain are characterized by semiarid climates, with annual precipitation generally lower than $300 \mathrm{~mm}$. Nevertheless, although the general features of climate in Spain are well-known, with several studies analyzing climate droughts (e.g. Vicente-Serrano, 2006b; Vicente-Serrano and Lopez-Moreno, 2006; Vicente- 
Serrano et al., 2014a), a comprehensive assessment of the spatial and temporal characteristics of drought events in Spain from a climatological point of view is still lacking. This includes a detailed spatial assessment of the differences in the frequency, duration and magnitude of drought episodes. Although few studies assessed the frequency of dry spells obtained from daily precipitation series (e.g. Martin-Vide and Gómez, 1999; Lana et al., 2008), they identified the spatial patterns of drought based on the general patterns of precipitation and aridity over the region.

Here we analyze -for the first time- the spatio-temporal characteristics of drought events in the mainland Spain and the Balearic Islands based on a very high-resolution $\left(1.21 \mathrm{~km}^{2}\right)$ spatial dataset spanning the period between 1961 and 2014. The overriding objectives of this study are to: i) determine the spatial differences in the characteristics of drought events over mainland Spain and the Balearic Islands; ii) explore differences in the observed spatial patterns as a function of the selected drought index (SPI vs. SPEI) as well as the different drought timescales (i.e. 1-, 3-, 6- and 12-months); and iii) identify the possible temporal changes in the characteristics of drought events and the spatial patterns of these changes.

\section{Data and Methods}

\subsection{Dataset}

We used a high-resolution $\left(1.21 \mathrm{~km}^{2}\right)$ weekly dataset of SPI and SPEI that covers the mainland Spain and the Balearic Islands between 1961 and 2014. The dataset was recently developed by Vicente-Serrano et al. (2017b) at timescales from 1- to 48-months, being publicly available through http://monitordesequia.csic.es. This dataset was developed using raw climatic data, including maximum and minimum air temperature (2269 observatories), precipitation totals (2269 observatories), wind speed (82 observatories), relative humidity (179 observatories) and sunshine duration (112 observatories). First, the grid of each variable 
was computed using the universal kriging interpolation algorithm (Borrough and McDonnell 1998; Pebesma, 2004), using latitude, longitude and elevation of each grid cell as auxiliary variables. Then, the gridded layers were validated using a jackknife resampling procedure (Phillips et al., 1992). The validation results demonstrate that the differences between the predicted and the observed values for each observatory were generally low (see VicenteSerrano et al., 2017b for further details). Based on the gridded data of air temperature, wind speed, relative humidity and sunshine duration, a gridded dataset was created for reference evapotranspiration (ETo) using the FAO-56 Penman-Monteith equation (Allen et al., 1998). The gridded data of precipitation and ETo were also used to calculate the Standardized Precipitation Index (SPI) (McKee et al., 1993) and the Standardized Precipitation Evapotranspiration Index (SPEI) (Vicente-Serrano et al., 2010) at a wide range of timescales (1- to 48-months). However, in this work, we restricted our analysis to SPI and SPEI timescales of 1-, 3-, 6- and 12.

\subsection{Methods}

Based on the gridded series of the SPEI and the SPI, we computed the series of drought events. Following the run theory (Yevjevich, 1967), there are several criteria to identify independent drought events based on thresholds (Fleig et al., 2006). These thresholds are arbitrary, unless they are based on objective metrics that relate a certain value of a drought index to specific sectorial impacts. However, this is practically impossible due to the large number of economic sectors and environmental systems affected by droughts on one hand and the varying responses of these sectors to different drought timescales on the other hand (Pasho et al., 2012; Lorenzo-Lacruz et al., 2013). In this study, an arbitrary threshold of SPEI and SPI equal to 0 was chosen. Although this threshold allows for the inclusion of dry periods with low duration and magnitude, it does not bias the analysis given our interest in 
characterizing drought events from a climatological point of view. As such, we defined drought events as $n$ consecutive weeks with values of the SPI or SPEI lower than 0. Once the drought events were identified, the corresponding series of drought duration and magnitude were computed. The drought duration was calculated as the number of consecutive weeks with SPEI or SPI values below 0. On the other hand, the drought magnitude was calculated following the classical approach of Dracup et al. (1980), in which the SPEI or SPI values are integrated over the full length of the dry period. Recalling that the values of the indices are negative, the total magnitude was transformed - for operative purposes- to positive values. Once the series of drought duration and magnitude were obtained for each grid point, we mapped the total number of drought events defined based on the SPI and the SPEI at the four timescales. For each grid point, we also computed the average drought duration and magnitude of drought events, and the values corresponding to the $90^{\text {th }}$ centile. The $90^{\text {th }}$ centile serves as a representative metric of the more or less extreme character of the dry events. The relationship between the different drought variables was assessed by means of scatterplots. To assess the statistical significance of the relationships between the spatial patterns of drought, we applied a bootstrap resampling approach that accounts for the high sampling size of our dataset (412.178 grid points). According to this procedure, we generated randomly a set of $10^{3}$ Monte Carlo simulations for each time series. These simulations were extracted from the gridded dataset by replacement with equal probability. For each grid point, the correlation matrix was computed using the $10^{3}$ series and the field significance was computed by averaging the $\mathrm{p}$-values of the correlations using all the simulated series.

To analyze the degree to which a trend of duration or magnitude of the drought events is consistently increasing or decreasing we used the nonparametric Mann-Kendall statistic, the statistical significance of the trends was assessed at the $90 \%$ level $(p<0.1)$. The MannKendall statistic is advantageous compared to parametric tests, as it is robust to outliers and 
does not assume any underlying probability distribution of the data (Zhang et al., 2001). For these reasons, it has been widely used for monotonic trend detection in a wide range of hydrological and climatological studies (e.g. Zhang et al., 2001; El Kenawy and McCabe, 2016). To account for any possible impact of autocorrelation on trend detection, we applied the modified Mann-Kendall trend test using the FUME package (Santander Metorology Group, 2012) within the R platform (R Core Team, 2017). This statistic returns the corrected p-values after accounting for temporal pseudo-replication (Hamed and Rao, 1998; Yue and Wang, 2004). This procedure is especially relevant when assessing temporal trends in SPI and SPEI at times scales higher than 1-month. Normally, the series at timescales higher than 1-month are impacted to some degree by temporal self-correlation (or temporal memory), which increases with the timescale considered. If self-correlation was not considered and a standard test assuming time independence was used, artificially low p-values would be obtained. To assess the amount of change in drought duration and magnitude, we used linear regression between the series of time (independent variable; expressed in weeks) and the drought duration or magnitude (dependent variable). The drought duration and magnitude was assigned to the week in which each drought episode was finished. The slope of the regression indicates the amount of change, with higher slope values indicating greater change.

\section{Results}

\subsection{Temporal evolution of seasonal and annual values of SPI and SPEI}

Figure 1 illustrates the evolution of the seasonal (i.e. DJF, MAM, JJA, SON) and annual SPI and SPEI, averaged over the mainland Spain and the Balearic Islands. The annual series show high variability, with no significant trends over the entire period. As depicted, more anomalous droughts were mainly noted in the 1990s and 2000s. These severe droughts were 
identified in all seasons, apart from autumn in which the most severe droughts were recorded in the 1980s. At annual scale, the most anomalous drought events, as revealed by both the SPI and SPEI, were observed in 1995 and 2005. While negative trends are mainly assigned to winter and summer, the trend is statistically significant only during summertime. On the other hand, spring shows no significant trend, meanwhile autumn exhibits a slightly positive trend. Figure 2 depicts the spatial distribution of the amount of change of the seasonal and annual SPI and SPEI. The annual amount of change is similar for SPI and SPEI, with a predominant negative trend over the whole study domain. Few exceptions are found along the Mediterranean coast and in the northern regions. For winter, spring and autumn, the trends are generally similar for SPI and SPEI, with a predominance of negative trends in winter and spring and positive trends during autumn. In summer, the amount of change shows consistent spatial patterns for SPI and SPEI, with negative trends in all the study domain, except for northwestern regions. Nevertheless, this pattern is intensified and more significant for SPEI, especially in the southern and central regions.

\subsection{Spatial characteristics of drought events}

Figure 3 illustrates the spatial distribution of the number of drought events. Notably, the number of drought events decreases as a function of the increase in the drought timescale. The total number of drought events during the study period exceeds 200, considering the 1month timescale, compared to 100-150 at the 3-months timescale and 50-100 at the 6-months timescale. As expected, the lowest number of dry events is recorded considering the 12 months, with values ranging between 20 and 80 . There are noticeable spatial differences in the number of drought events, combined with contrasts among the drought timescales. In general, irrespective of the drought index and the timescale, the northern region of Spain exhibits a higher number of drought events, compared to other regions. This north-south 
gradient is particularly evident at 1- and 3-months timescales using SPEI. In contrast, SPI and other timescales of SPEI show less clear spatial gradients, with lower frequency of drought events in central (6-months) and southwestern (12-months) Spain. Although there is a high degree of consistency between the observed spatial patterns using SPI and the SPEI, this agreement is not perfect. At the 12-months timescale, the maximum Pearson's $r$ correlation coefficient does not exceed 0.79 (Figure 4). In general, the SPI tends to record a higher number of events than SPEI, with the exception of the 12-months timescale, in which both indices show a similar number of events.

The spatial distribution of the average duration and the magnitude of the drought events (Figures 5 and 6, respectively) was inversely proportional to the spatial distribution of the number of events (Figure 3). The average duration and magnitude was therefore shorter in northern Spain, independently of the drought timescale. On the contrary, the average duration and magnitude was more than double in some areas of the central and southwestern Spain. Notably, the average drought duration in southwestern Spain is higher than 32 weeks at the 12-months timescale, compared to only 14 weeks in northern Spain.

There is a strong relationship between the spatial patterns of the average duration and magnitude (Pearson's $r$ correlation coefficients above 0.9), irrespective of the drought index and the timescale (Figure 7). The only exception is the 1-month SPI, at which a lower association is found (Pearson's $r=0.7$ ). Moreover, there are some differences in the average magnitude and duration of the drought events, as suggested by both SPI and SPEI (Figure 8). As illustrated, the 1-, 3- and 6-months timescales show higher duration and magnitude of the drought events for the SPEI than for the SPI. These differences are small, though being statistically significant. In contrast, at the 12-months timescale, there are statistically significant differences between the SPI and SPEI, with higher duration and magnitude of drought events for the SPI than for the SPEI. 
In order to determine the spatial frequency of drought events with high duration and magnitude, we calculated the $90^{\text {th }}$ centile of the duration and magnitude series at each grid cell. As illustrated in Figure 9, the spatial distributions of the $90^{\text {th }}$ centile calculated for drought duration closely resemble those of the average values (Figure 5). However, there are some spatial differences, as a function of the selected drought index and timescale. For example, more than $10 \%$ of the drought events recorded in southwestern Spain at 1-month SPEI exhibit a duration of more than 15 consecutive weeks. In the meantime, this region shows a duration higher than 90 weeks using the $90^{\text {th }}$ centile at 12 -months timescale, which are clearly reinforced considering the SPI. Again, there is a good agreement between the spatial patterns of the $90^{\text {th }}$ centiles of drought magnitude (Figure 10), but with spatial differences as a function of the drought timescale.

\subsection{Temporal evolution of drought duration and magnitude}

The analysis of the temporal evolution of drought events duration and magnitude averaged over the whole domain did not reveal significant trends, either using the SPI or the SPEI (Table 1). Table 2 shows the percentage of the surface with positive and negative trends in drought duration and magnitude. Independently of the drought index and timescale, the nonsignificant (either positive or negative) trends predominate. The percentage of surface showing statistically significant positive trends in the duration of drought events varies between 2.98 (6-months SPI) and 13.23\% (1-month SPEI). Similarly, the surface with statistically significant negative trends in drought magnitude oscillates between $1.45 \%$ (6months SPEI) and 14.6\% (1-month SPI). Notably, the surface affected by statistically significant positive trends is higher for the SPEI than for the SPI for both the magnitude and duration series, and for all timescales as well. 
The observed differences in the average duration (Figure 11) and magnitude (Figure 12) between the end and the beginning of the period of analysis show strong spatial variability, as a function of the drought timescale and the drought index. Positive differences in the drought duration at the 1- and 3-months timescales dominate over northeastern Spain, being stronger for the SPEI than for the SPI. The duration of drought events at the 3-months timescale increases in these regions by almost one week per decade since 1961. On the contrary, a decrease of duration is found over large areas of the Mediterranean coastland. At 6- and 12months timescales, central, southern and northeastern Spain show an increase in the duration of drought events, on the order of more than 6 weeks per decade between 1961 and 2014 (12months timescale). These patterns are spatially consistent with those observed for drought magnitude (Figure 12), but with a remarkable increae using the SPEI at all considerd timescales. This feature can be observed for the 1-, 3- and 6-months timescales (Figure 13). As illustrated, the frequency of positive differences (i.e. more duration and magnitude of drought events) is higher for the SPEI than for the SPI. At the 12-months timescale, these differences are much lower, although both indices suggest positive differences and accordingly an intensification of drought severity.

Significant correlations are found between the differences in drought events duration and magnitude obtained with the SPEI and the SPI (Figure 14). These correlations are higher considering 1- and 3-months timescales, compared to 12-months SPEI and SPI. Overall, it can be noted that the clouds of points were biased toward more positive values for the SPEI than for the SPI.

\section{Discussion and conclusions}

This study presents the first climatology of drought events for mainland Spain and the Balearic Islands, considering different drought timescales (1-,3-,6- and 12-months) and two 
different drought indices: the Standardized Precipitation Index (SPI) and the Standardized Precipitation Evapotranspiration Index (SPEI). This study benefits from a recently developed high spatial resolution $\left(1.2 \mathrm{~km}^{2}\right)$ gridded dataset of drought indices over Spain.

Our study shows strong spatial differences in the frequency and the average duration and magnitude of the drought events. In general, there is a north-south gradient, irrespective of the drought index or the drought timescale. Drought espisodes are more frequent in northern Spain, compared to cental and southern Spain. In contrast, drought duration tends to be shorter in the north, and the magnitude tends to be lower. Moreover, although there are some spatial differences among drought timescales in the areas with lower frequency and higher duration and magnitude. Indeed, this pattern does not imply that northern Spain cannot record drought episodes of special severity. In 1990, the large cities of northern Spain suffered from water restrictions due to extremely severe drought events.

Climatic characteristics explain the observed spatial differences in drought events. Northern and northeastern regions are more humid, mainly influenced by low pressure systems associated with the Polar front (Serrano et al., 1999), besides other numerous meteorological mechanisms (Llasat and Puigcerver, 1997; Campins et al., 2000). This explains shorter drought events in the northern regions, where drought events terminate quickly and replaced frequently by humid conditions. On the contrary, central and southern Spain are less impacted by synoptic conditions favorable for precipitation, and converserly highly influenced by subtropical highs (Serrano et al., 1999), which tends to have a stronger persistence.

Although these spatial patterns are generally consistent at different drought timescales, they also show some considerable differences. The reasons of these differences are unclear and further research is needed to establish the possible causes. A possible reason might be the different influence of atmospheric circulation quantified at different spatial scales. One 
hypothesis, that needs to be validated, is that the persistent anomalies in the atmospheric conditions may drive the variability of droughts at short timescales (i.e. 1-3 months), whereas longer drought timescales can be more influenced by anomalies in the general (continental/hemispheric) circulation patterns. Since the influence of weather types and atmospheric circulation mechanisms on precipitation in Spain is quite complex (RodríguezPuebla et al., 1998; Serrano et al., 1999; Valero et al., 2004; Martín et al., 2004; VicenteSerrano and López-Moreno, 2006), it is reasonable that this complexity translates to droughts characteristics. In any case, these results also stress the strong complexity of drought episodes in Spain. On one hand, the general spatial patterns of drought indices show strong differences, as a function of the timescales. This coincides with the results shown in VicenteSerrano (2006b), who pointed out that drought spatial patterns vary considerably in relation to the different temporal influence of precipitation events recorded at local/regional spatial scales.

Moreover, the use of two different drought indices has allowed for establishing the spatial differences among them. In general, the spatial patterns of the average drought duration and magnitude seem to be similar for the SPEI and the SPI. Nevertheless, drought duration and magnitude were in general higher for the SPEI than for the SPI. This is mostly evident at the 1-month timescale, but also at the 3-and 6-months timescales. This finding can be explained by the influence of the atmospheric evaporative demand (AED) on drought severity, which is included only in the SPEI calculations and not in the SPI. This has been observed in different drought episodes in Europe during the last two decades. For example, the 2003 drought that affected Central and Western Europe was accompanied by high temperatures that exacerbated AED and caused a strong reduction of carbon sequestration in the region (Ciais et al., 2005). The importance of a feedback effect between drought and AED was also described in central Russia in 2010 (Barriopedro et al., 2012), and Western Europe in 2017 
(Sánchez-Benítez et al., 2018), where drought severity was enhanced by thermodynamic processes that reinforced the AED. Nevertheless, we also noted that the differences among the SPI and SPEI get lower as timescale increases. As such, the average duration and magnitude of the drought events tended to be higher for the SPI than for the SPEI at 12months timescale. This implies that the influence of AED on drought duration and magnitude seems to be dependent on the drought timescale.

Several studies in Spain (e.g. Vicente-Serrano et al., 2014a) and Southern Europe (e.g. Stagge et al., 2017) suggested that drought indices that account for precipitation and the AED (e.g. the SPEI) show different temporal behavior over the past decades, compared to those indices based only on precipitation (e.g. the SPI). As opposed to the SPI, the SPEI reveals a tendency toward more decrease (i.e. more negative values and accordingly more drought conditions). Other authors suggested an increase in drought severity in the Mediterranean region using drought indices based only on precipitation (e.g. Hoerling et al., 2012). However, over the Iberian Peninsula, long term changes did not show a significant trend (Vicente-Serrano, 2013). For the mainland Spain and the Balearic Islands, this study also demonstrates no significant changes in drought duration and magnitude at the regional scale for both the SPI and SPEI. Even for the increase found for some instances at the 12-months timescale, this increase was statistically non-significant. At the grid scale, our results indicate that the positive trends (towards higher duration and magnitude) prevail in the study domain, compared to negative trends. The surface affected by positive trends in the magnitude and duration of the drought events was much higher considering the SPEI than the SPI. This pattern was found at both short and long timescales. A possible explanation of the increase in positive trends can be the observed increase in the AED during the last decades (VicenteSerrano et al., 2014b). This implies that the severity of drought events, mainly attributed to precipitation deficit, can be aceletrated due to high AED. This explaines why some areas of 
Spain show strong changes in the duration and magnitude of drought episodes when considering the SPEI.

To conclude, it is important to stress that despite the absence of significant trends at the regional scale over Spain, there are important spatial differences, with strong changes in the duration and the magnitude of drought events, mostly in the northeastern and southern Spain. These regions suffered from critical water availability issues during the severe drought episodes that occurred over the last two decades (Vicente-Serrano et al., 2017a). This study provides a detailed spatial assessment of drought characteristics over Spain using highresolution spatial data, spanning the past five decades. Such assessment can provide guidance to stakeholders and decision-makers on detecting, monitoring and adapting to drought impacts in different sectors (e.g. crop yield, agriculture, water resources management).

\section{Acknowledgements}

This work was supported by the research projects CGL2014-52135-C03-01 and PCIN-2015220 financed by the Spanish Commission of Science and Technology and FEDER, 1560/2015: Herramientas de monitorización de la vegetación mediante modelización ecohidrologica en parques continentales financed by the Red de Parques Nacionales, IMDROFLOOD financed by the Water Works 2014 co-funded call of the European Commission and INDECIS, which is part of ERA4CS, an ERA-NET initiated by JPI Climate, and funded by FORMAS (SE), DLR (DE), BMWFW (AT), IFD (DK), MINECO (ES), ANR (FR) with co-funding by the European Union (Grant 690462). Marina PeñaGallardo was granted by the Spanish Ministry of Economy and Competitiveness(MINECO), Miquel Tomas-Burguera was supported by a doctoral grant by the Spanish Ministry of Education, Culture and Sport and Ahmed El Kenawy was supported by a postdoctoral Juan de la Cierva contract by the Spanish Ministry of Economy and Competitiveness (MINECO). 


\section{References}

Allen, R. G., Pereira, L.S., Raes, D. \& Smith, M. (1998). Crop evapotranspiration: Guidelines for computing crop water requirements. FAO, 300, D05109.

Barriopedro, D., Gouveia, C. M., Trigo, R. M., Wang L. (2012). The 2009/10 drought in China: possible causes and impacts on vegetation. J. Hydromet., 13(4): 1251-1267.

Borrough, P. A. \& McDonnell, R. A. (1998). Principles of Geographical Information Systems. UK, Oxford University Press.

Camarero, J. J., Gazol, A., Sangüesa-Barreda, G., Oliva, J., \& Vicente-Serrano S. M. (2015a). To die or not to die: early warnings of tree dieback in response to a severe drought. $J$. Ecol., 103(1): 44-57.

Camarero, J. J., Franquesa, M. \& Sangüesa-Barreda, G. (2015b). Timing of drought triggers distinct growth responses in holm oak: implications to predict warming-induced forest defoliation and growth decline. Forests, 6(5): 1576-1597.

Campins, J., Genoves, A., Jansa, A., Guijarro, J. A. \& Ramis, C. (2000). A catalogue and a classification of surface cyclones for the Western Mediterranean. Int'l J. Climatol., 20: $969-984$.

Ciais, P., Reichstein, M., Viovy, N., Granier, A., Ogée, J., Allard, V., ... Valentini R. (2005). Europe-wide reduction in primary productivity caused by the heat and drought in 2003. Nature, 437: 529-533.

Domínguez-Castro, F., de Miguel J. C., Vaquero, J. M., Gallego, M. C., \& García-Herrera, R. (2014). Climatic potential of Islamic chronicles in Iberia: Extreme droughts (AD 7111010). The Holocene, 24(3): 370-774.

Domínguez-Castro, F., Santisteban, J. I., Barriendos, M., \& Mediavilla, R. (2008).

Reconstruction of drought episodes for central Spain from rogation ceremonies recorded at Toledo Cathedral from 1506 to 1900: A methodological approach. Global and Planetary Change, 63: 230-242.

Dracup, J. A., Lee, K. S. \& Paulson, E. G. Jr. (1980). On the definition of droughts. Water Resour. Res., 16(2): 297-302.

Fleig, A. K., Tallaksen, L. M., Hisdal, H. \& Demuth, S. (2006). A global evaluation of streamflow drought characteristics. Hydrol. and Earth Syst. Sci., 10: 532-552. 
García-Herrera, R., Paredes, D., Trigo, R. M., Trigo I. F., Hernández E., Barriopedro, D. \& Mendes, M. A. (2007). The outstanding 2004/05 drought in the Iberian Peninsula: Associated atmospheric circulation. J. Hydromet., 8(3): 483-498.

Gil M., Garrido, A. \& Gómez-Ramos, A. (2011). Economic analysis of drought risk: An application for irrigated agriculture in Spain. Agri. Water Mgmt., 98(5): 823-833.

Gouveia, C. M., Bastos, A., Trigo, R. M., \& DaCamara C. C. (2012). Drought impacts on vegetation in the pre-and post-fire events over Iberian Peninsula. Natural Haz. and Earth Syst. Sci., 12(10): 3123-3137.

Hamed, K. H. \& Rao, A. R. (1998). A modified Mann Kendall trend test for autocorrelated data. J. Hydrol., 204: 182-196.

Hoerling, M., Eischeid, J., Perlwitz, J., Quan, X., Zhang, T., \& Pegion, P. (2012). On the increased frequency of Mediterranean drought. J. Clim., 25(6): 2146-2161.

Kenawy, A. \& McCabe, M. F. (2016). A multi-decadal assessment of the performance of gauge- and model-based rainfall products over Saudi Arabia: climatology, anomalies and trends. Int'l J. Climatol., 36: 656-674.

Lana, X., Martínez, M. D., Burgueño, A., Serra, C., Martín-Vide, J. \& Gómez, L. (2008). Spatial and temporal patterns of dry spell lengths in the Iberian Peninsula for the second half of the twentieth century. Theor. and Appl. Climatol., 91: 99-116.

Llasat, M. C. \& Puigcerver, M. (1997). Total rainfall and convective rainfall in Catalonia, Spain. Int'l J. Climatol., 17(15): 1683-1695.

Lorenzo-Lacruz, J., Morán-Tejeda, E., Vicente-Serrano, S. M. \& López-Moreno J. I. (2013). Streamflow droughts in the Iberian Peninsula between 1945 and 2005: spatial and temporal patterns. Hydrol. and Earth Syst. Sci., 17(1): 119-134.

Lorenzo-Lacruz, J. \& Morán-Tejeda, E., (2016). Spatio-temporal patterns of meteorological droughts in the Balearic Islands (Spain). Cuad. de Inv. Geog., 42(1): 49-66.

Lorenzo-Lacruz, J., Garcia, C. \& Morán-Tejeda E. (2017). Groundwater level responses to precipitation variability in Mediterranean insular aquifers. J. Hydrol., 552: 516-531.

Martín, M. L., Luna M. Y., Morata A. \& Valero F. (2004). North Atlantic teleconnection patterns of low-frequency variability and their links with springtime precipitation in the Western Mediterranean. Int'l J. Climatol., 24: 213-230.

Martín-Vide, J. \& Gómez, L. (1999). Regionalization of Peninsular Spain based on the length of dry spells. Int'l J. Climatol., 19: 537-555.

Martin-Vide, J. \& Lopez-Bustins, J. A. (2006). The Western Mediterranean Oscillation and rainfall in the Iberian Peninsula. Int'l J. Climatol., 26(11): 1455-1475. 
Martín-Vide, J. \& Olcina J. (2001). Climas y tiempos de España. España, Alianza Editorial. McKee, T. B. N., Doesken, J. \& Kleist, J. (1993). The relationship of drought frequency and duration to time scales. In Proceedings of the 8th Conference on Applied Climatology, Anaheim, CA, USA, 17-22 January 1993; pp. 179-183.

Morales, A., Olcina, J. \& Rico, A. M. (2000). Diferentes percepciones de la sequía en España: adaptación, catastrofismo e intentos de corrección. Inv. Geog., 23: 5-46.

Páscoa, P., Gouveia, C. M., Russo, A. \& Trigo, R. M. (2017). The role of drought on wheat yield interannual variability in the Iberian Peninsula from 1929 to 2012. Int'l J. Biomet., 61(3): 439-451.

Pasho, E., Camarero J. J. \& Vicente-Serrano S. M. (2012). Climatic impacts and drought control of radial growth and seasonal wood formation in Pinus halepensis. Trees: Structure and Function, 26: 1875-1886.

Pausas J.G. (2004). Changes in fire and climate in the eastern Iberian Peninsula (Mediterranean Basin). Climatic Change, 63: 337-350.

Pausas J. G., \& Fernández-Muñoz S. (2012). Fire regime changes in the Western Mediterranean Basin: from fuel-limited to drought-driven fire regime. Climatic Change, 110(1-2): 215-226.

Pebesma, E. J. (2004). Multivariable geostatistics in S: The gstat package. Comput. Geosci., 30: 683-691.

Peña-Gallardo, M., Vicente-Serrano, S. M., Camarero et al. (2018). Drought sensitiveness on forest growth in peninsular Spain and the Balearic Islands. Forests, 9(9): 524

Peña-Gallardo, M., Vicente-Serrano, S. M., Domínguez-Castro, F. and Beguería, S. (2019). The impact of drought on the productivity of two rainfed crops in Spain. Nat. Haz. Earth Syst. Sci. Discuss. doi: 10.5194/nhess-2019-1 [in review]

Phillips, D. L., Dolph, J. \& Marks, D. (1992). A comparison of geostatistical procedures for spatial analysis of precipitation in mountainous terrain. Agri. Meteorol., 58: 119-141.

R Development Core Team, 2017. R: a language and environment for statistical computing. R Foundation for Statistical Computing, Vienna, Austria. http://www.R-project.org [accessed 28.05.18]

Rodriguez-Puebla, C., Encinas, A. H., Nieto, S. \& Garmendia, J. (1998). Spatial and temporal patterns of annual precipitation variability over the Iberian Peninsula. Int'l J. Climatol., 18(3): 299-316. 
Sánchez-Benítez, A., García-Herrera, R., Barriopedro, D., Sousa, P. M., Trigo R. M. (2018). June 2017: The earliest European summer mega-heatwave of reanalysis period. Geophys. Res. Letts., 45(4): 1955-1962.

Santander Meteorology Grup, (2012). Fume: FUME package. R package version 1.0. https://cran.r-project.org/src/contrib/Archive/fume [accessed 28.05.2018]

Serrano, A., García, J. A., Mateos, V. L., Cancillo, M. L., Garrido, J. (1999). Monthly modes of variation of precipitation over the Iberian Peninsula. J. Clim., 12: 2894-2919.

Stagge, J. H., Kingston, D. G., Tallaksen, L. M. \& Hannah, D. M. (2017). Observed drought indices show increasing divergence across Europe. Scientific Reports, 7: 14,045.

Tejedor, E., de Luis, M., Cuadrat, J. M., Esper, J. \& Saz, M. A. (2016). Tree-ring-based drought reconstruction in the Iberian Range (east of Spain) since 1694. Int'l J. Biomet., 60: 361-372.

Tejedor, E., Saz, M. A., Esper, J., Cuadrat, J. M. \& de Luis, M. (2017). Summer drought reconstruction in northeastern Spain inferred from a tree ring latewood network since 1734. Geophys. Res. Lett., 44: 8492-8500.

Trigo, R. M., Pozo-Vázquez, D., Osborn, T. J., Castro-Díez, Y., Gámiz-Fortis, S., EstebanParra, M. J. (2004). North Atlantic Oscillation influence on precipitation, river flow and water resources in the Iberian Peninsula. Int'l J. Climatol., 24(8): 925-944.

Trigo, R. M., Añel, J. A., Barriopedro, D., García-Herrera R., Gimeno L., Nieto, R., ... Massey, N. (2013). The record winter drought of 2011-12 in the Iberian Peninsula. Bull. Am. Met. Soc., 94(9): 41-45.

Turco, M., von Hardenberg, J., AghaKouchak, A., Llasat, M. C., Provenzale, A. \& Trigo R. M. (2017). On the key role of droughts in the dynamics of summer fires in Mediterranean Europe. Scientific Reports, 7: 81.

Valero, F., Luna, M. Y., Martín, M. L., Morata A. \& González-Rouco F. (2004). Coupled modes of large-scale climatic varibles and regional precipitation in the Western Mediterranean in autumn. Clim. Dyn., 22: 307-323.

Vicente-Serrano, S. M. (2006a). Spatial and temporal analysis of droughts in the Iberian Peninsula (1910-2000). Hydrol. Sci. J., 51(1): 83-97.

Vicente-Serrano, S. M. (2006b). Differences in spatial patterns of drought on different time scales: an analysis of the Iberian Peninsula. Water Resour. Mgmt., 20(1): 37-60. 
Vicente-Serrano, S. M. (2013). Spatial and temporal evolution of precipitation droughts in Spain in the last century. In Adverse Weather in Spain, Martínez, C. C.-L., Rodríguez, F. V. (Eds.), 283-296.

Vicente-Serrano, S. M. \& López-Moreno J. I. (2006). The influence of atmospheric circulation at different spatial scales on winter drought variability through a semi-arid climatic gradient in northeast Spain. Int'l J. Climatol., 26(11): 1427-1453.

Vicente Serrano, S. M. \& Cuadrat, J. M. (2007). North Atlantic oscillation control of drought in north-east Spain: evaluation since 1600 A.D. Climatic Change, 85: 357-379.

Vicente-Serrano, S. M., Cuadrat-Prats, J. M. \& Romo, A. (2006). Early prediction of crop production using drought indices at different time-scales and remote sensing data: application in the Ebro Valley (north-east Spain). Int'l J. Remote Sens., 27(3): 511518.

Vicente-Serrano, S. M., Lopez-Moreno, J. I, Beguería, S., Lorenzo-Lacruz, J., SanchezLorenzo A., García-Ruiz J. M., ... Espejo F. (2014a). Evidence of increasing drought severity caused by temperature rise in southern Europe. Env. Res. Letts., 9: 044001.

Vicente-Serrano, S. M., Azorin-Molina, C., Sanchez-Lorenzo, A., Revuelto, J., LópezMoreno, J. I., González-Hidalgo J. C., \& Espejo F. (2014b). Reference evapotranspiration variability and trends in Spain, 1961-2011. Global and Planetary Change, 121: 26-40.

Vicente-Serrano, S. M., Rodríguez-Camino, E., Domínguez-Castro, F., El Kenawy, A. \& Azorín-Molina, C. (2017a). An updated review on recent trends in observational surface atmospheric variables and their extremes over Spain. Cuad. de Inv. Geog., 43: 209-232.

Vicente-Serrano, S. M., Tomas-Burguera, M., Beguería, S., Reig, F., Latorre, B., PeñaGallardo, M., ... Gómez-Hidalgo J. C. (2017b). A high resolution dataset of drought indices for Spain. Data, 2: 22.

Yevjevich, V. M. (1967). An objective approach to definition and investigation of continental hydrologic droughts. Hydrologic paper 23. Universidad de Colorado.

Yue, S., \& Wang, C. (2004). The Mann-Kendall Test Modified by Effective Sample Size to Detect Trend in Serially Correlated Hydrological Series. Water Resour. Mgmt., 18: 201-218.

Zhang, X., Harvey, K. D., Hogg, W. D., Yuzyk, T. R. (2001). Trends in Canadian streamflow. Water Resour. Res., 37(4): 987-998. 

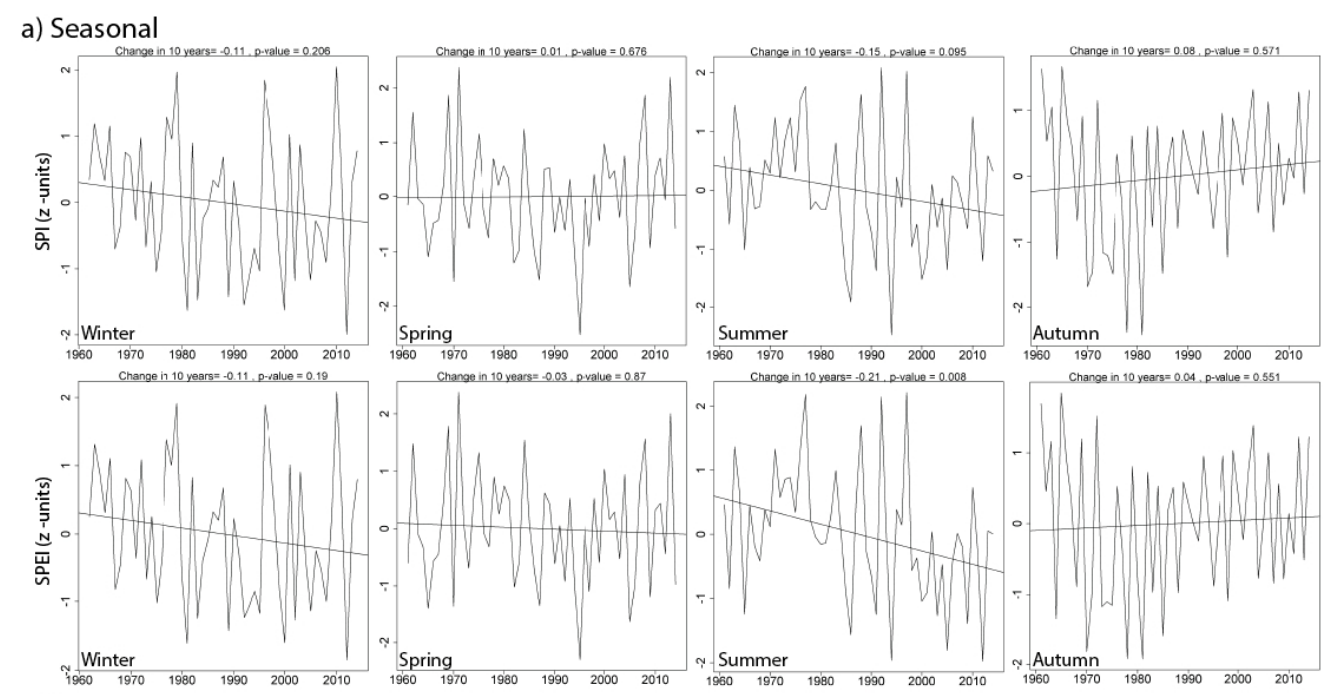

b) Annual
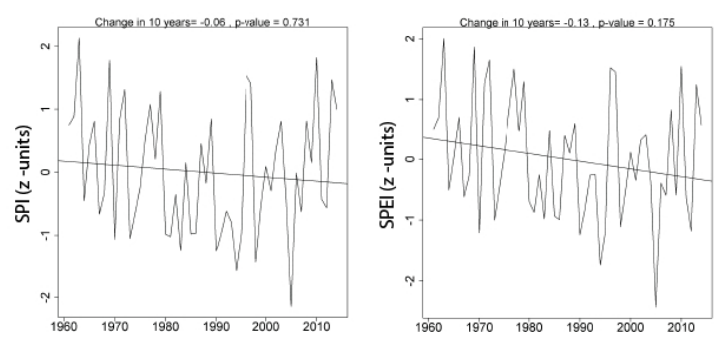

Figure 1: Temporal evolution of the (a) seasonal and (b) annual SPI and SPEI series averaged for the whole study domain. Seasonal SPI and SPEI are obtained from 3-months time scale considering the value of the last month of the season and Annual indices are obtained from 12-months time scale in December. 

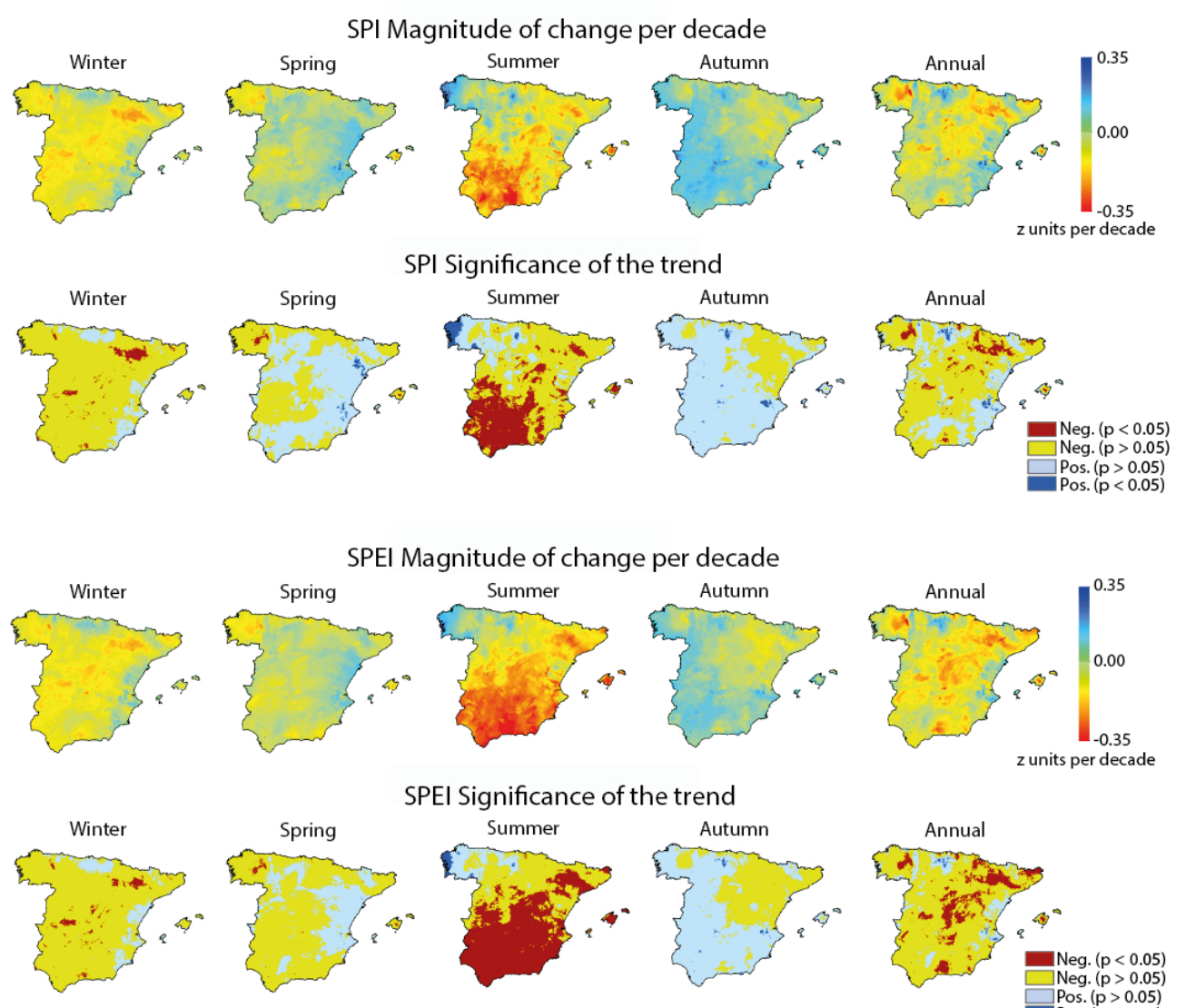

SPEI Significance of the trend
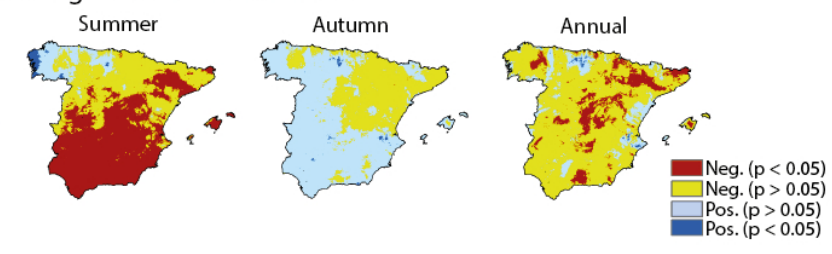

Figure 2: Seasonal and annual amount of change ( $Z$ unit/decade) in the SPI and SPEI and their statistical significance. 

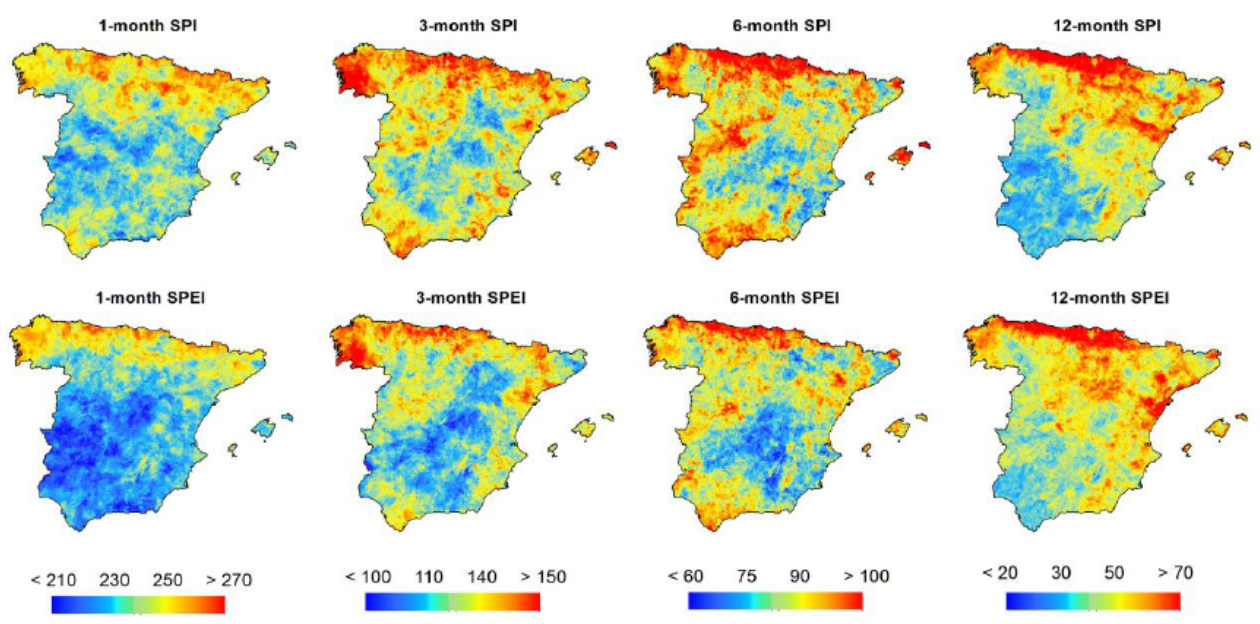

Figure 3: Spatial distribution of the number of drought events considering the SPI and SPEI at the timescales of 1-, 3-, 6- and 12-month. 

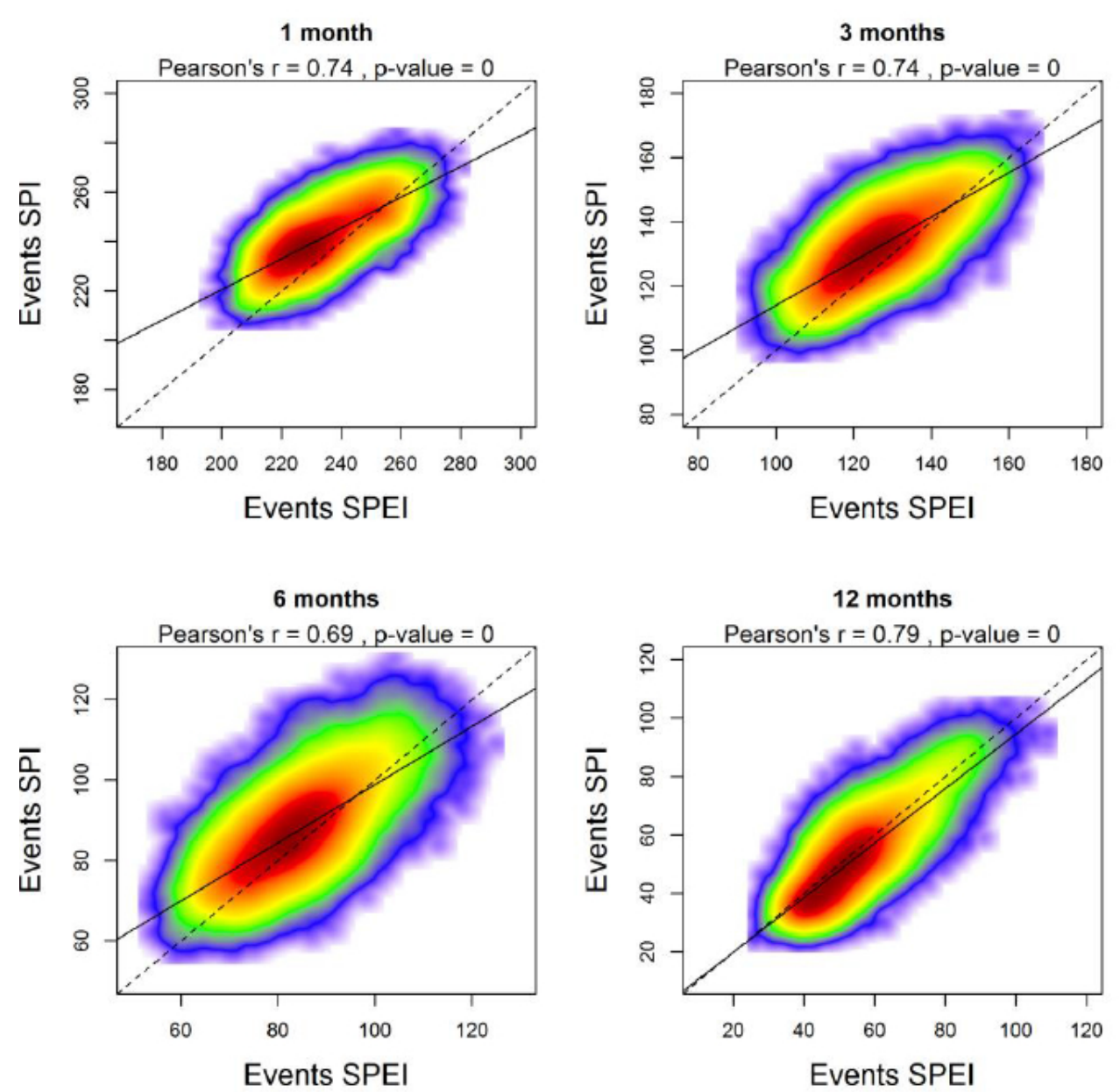

Figure 4: Relationships between the number of drought events recorded with the SPI and SPEI series at timescales of $1-, 3-, 6-$ and 12-month. 

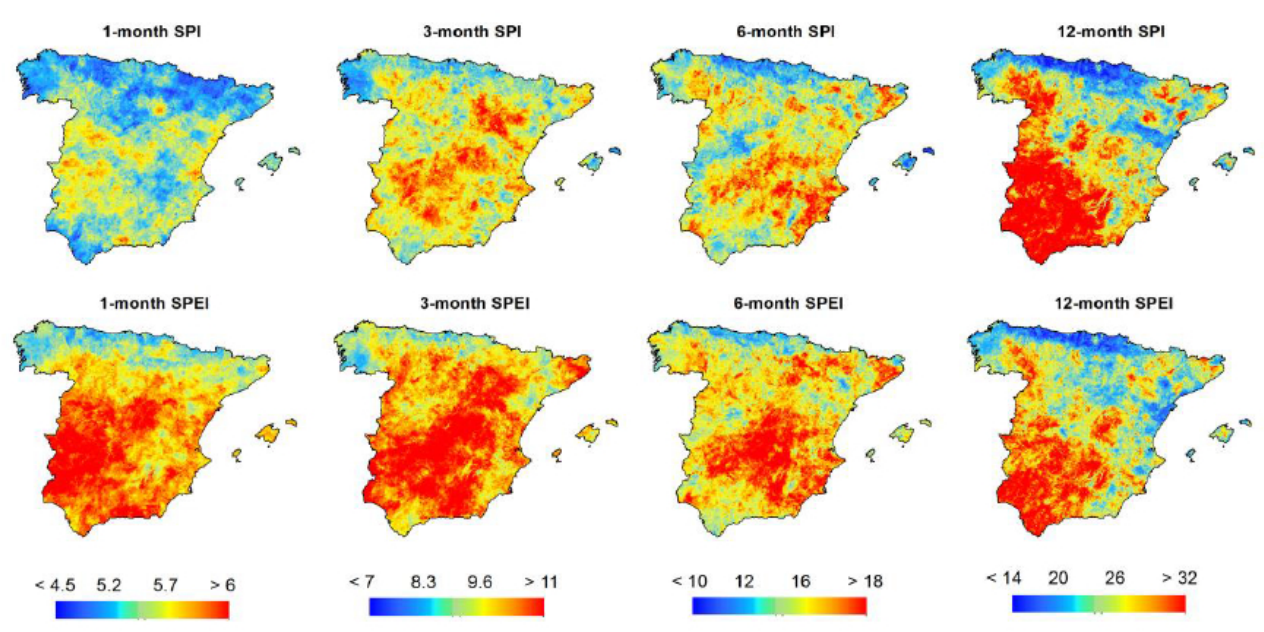

Figure 5: Spatial distribution of the average duration (weeks) of the drought events considering both SPI and SPEI at the timescales of 1-, 3-, 6- and 12-months. 

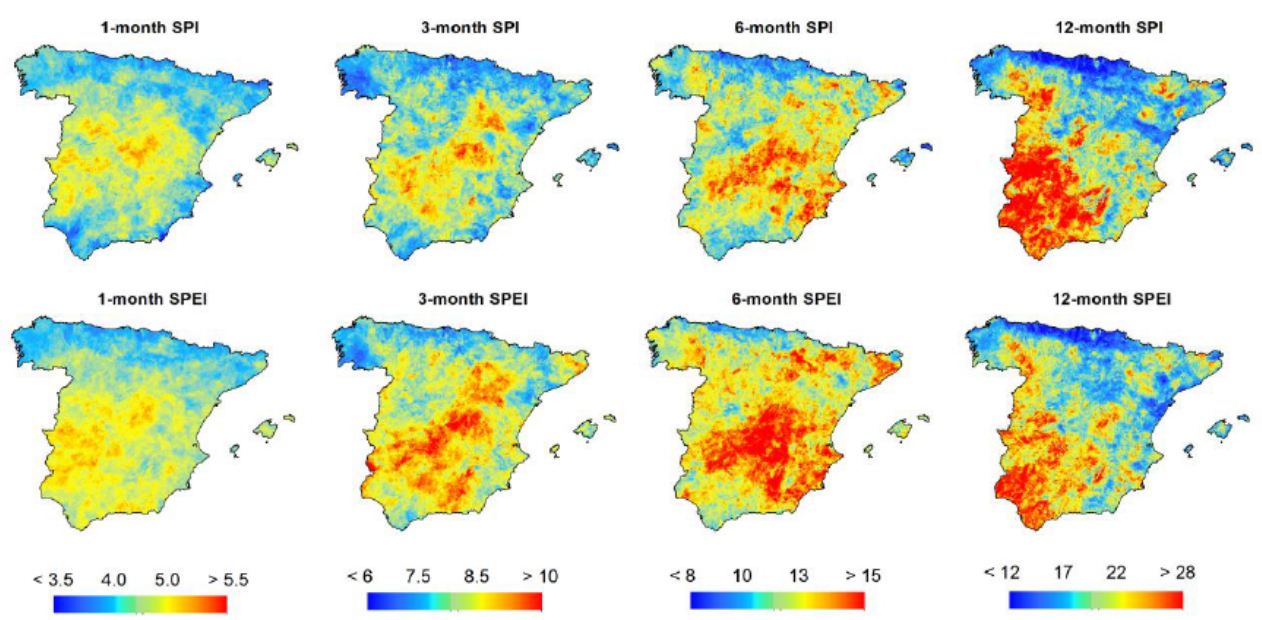

Figure 6: Spatial distribution of the average magnitude of the drought events considering both SPI and SPEI at the timescales of $1-, 3-, 6-$ and 12-months. 

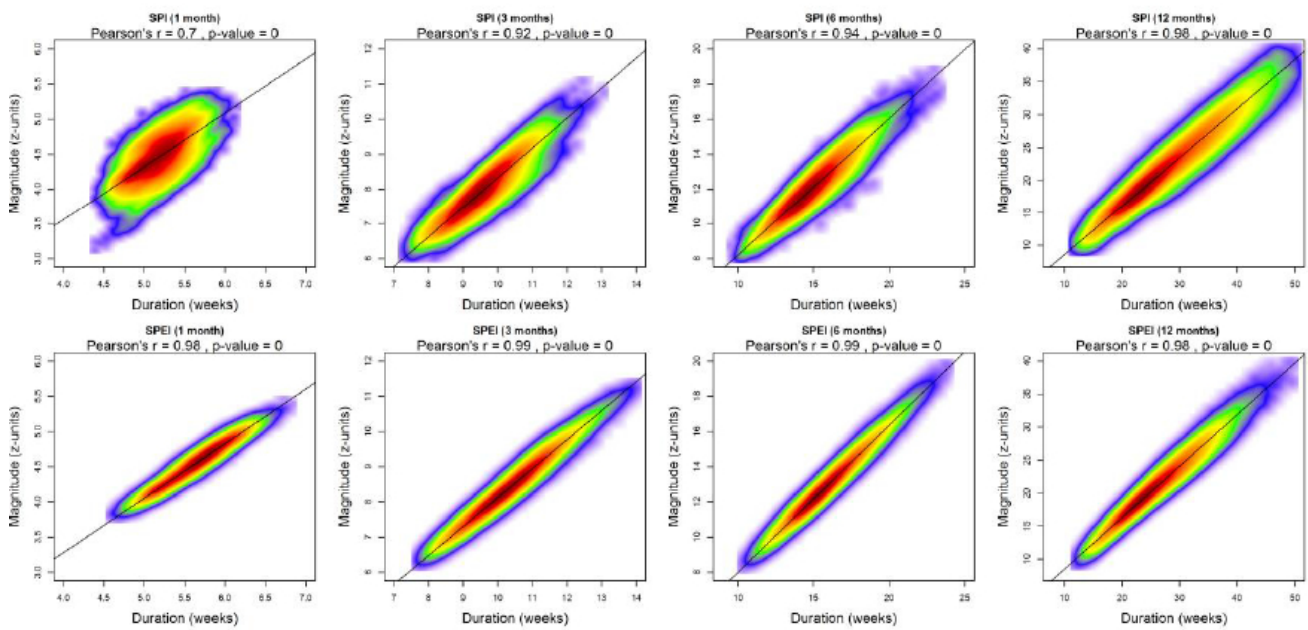

Figure 7: Relationships between the average duration and magnitude of drought events considering timescales of 1-, 3-, 6- and 12-months and both drought indices (SPEI and SPI). 

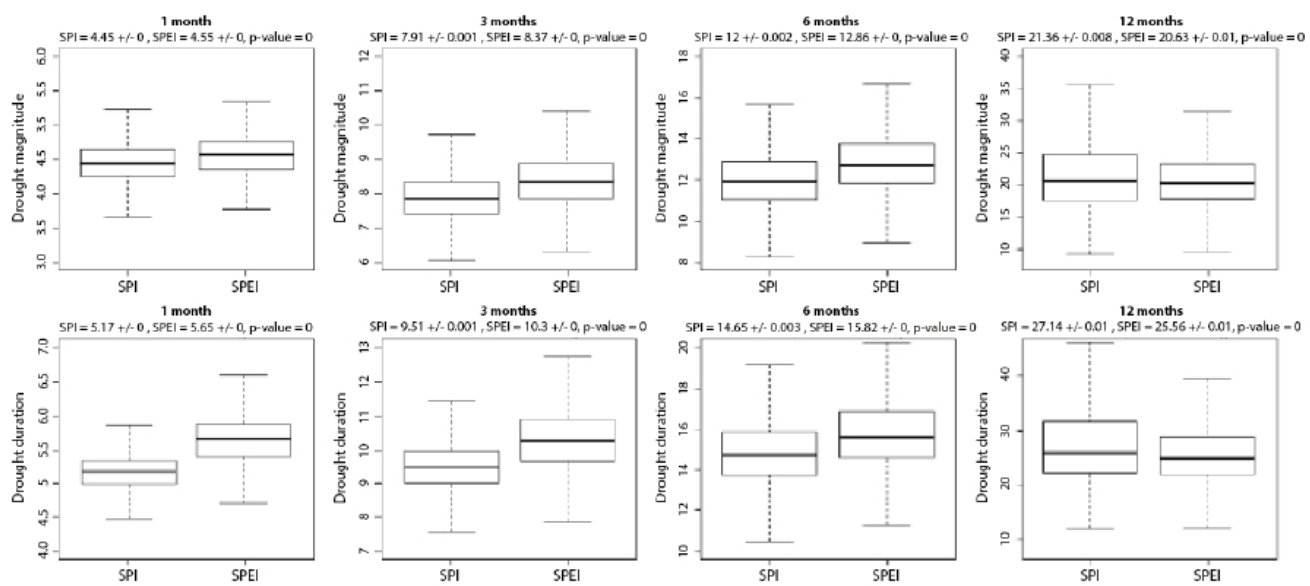

Figure 8: Boxplots showing the series of drought duration and magnitude for 1-, 3-, 6- and 12-months using the SPEI and SPI. The central solid line indicates the median. The whiskers represent the 10th and the 90th, while the 25th and the 75th are plotted as the vertical lines of the bounding boxes. Signification of the average values was assessed by means of an Analysis of Variance. 

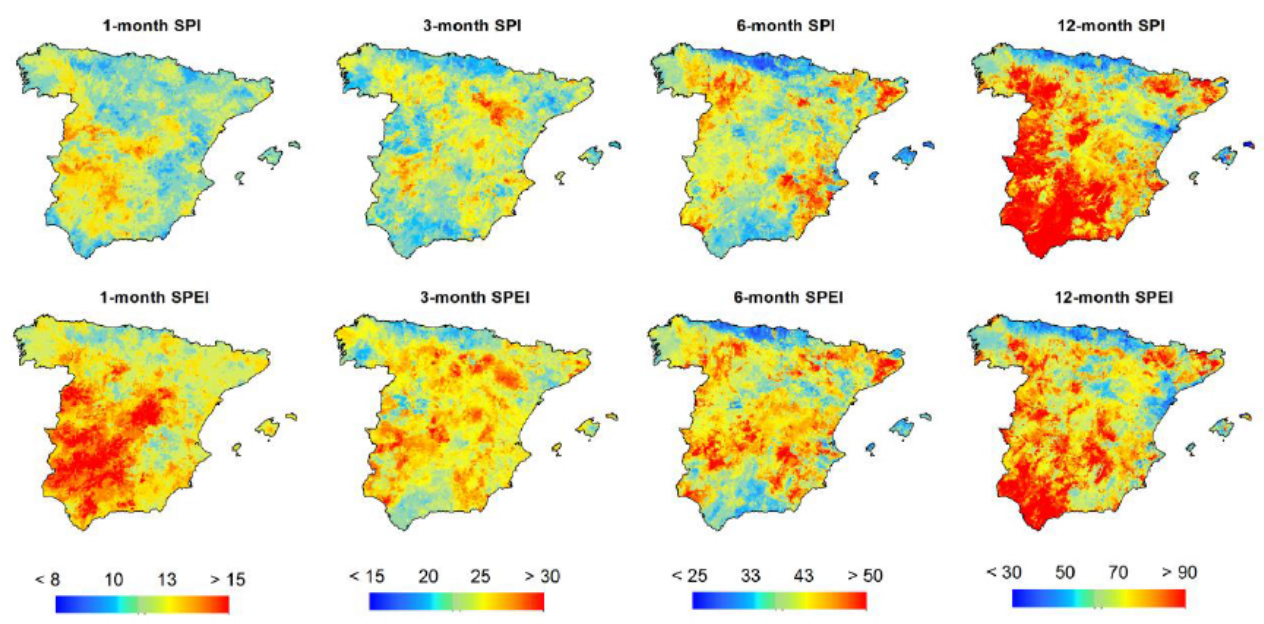

Figure 9: Spatial distribution of the 90th centile of drought duration series. 

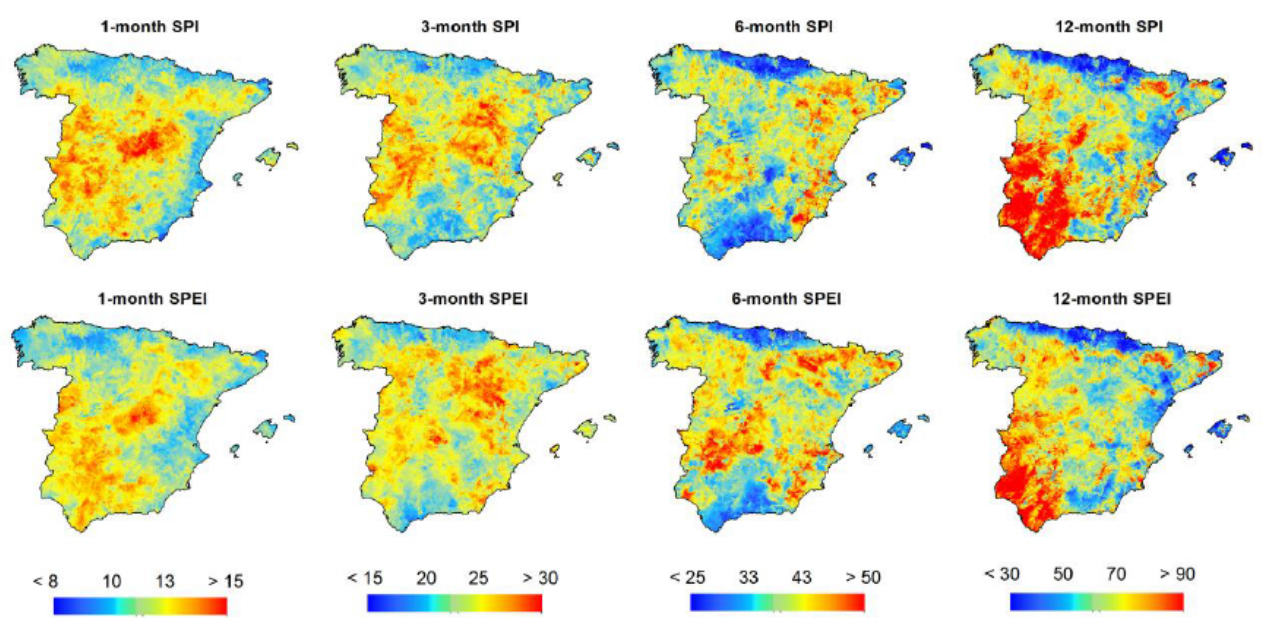

Figure 10: Spatial distribution of the 90th centile of drought magnitude series. 
(a)
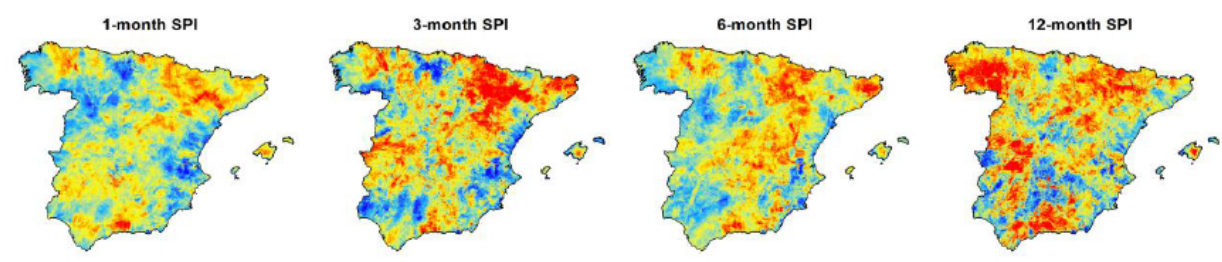

1-month SPEI
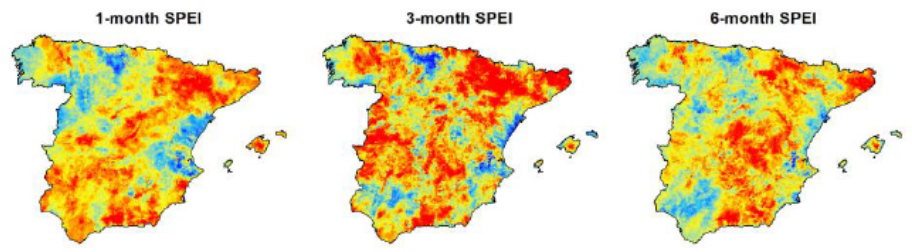

12-month SPEI

$\begin{array}{cccc}-0.5 & -0.25 & 0.25 & >0.5\end{array}$
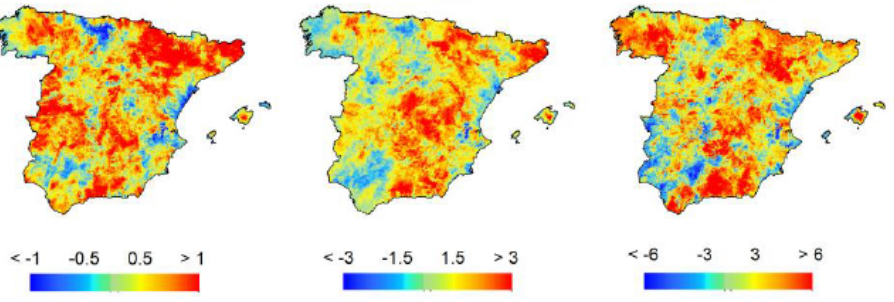

(b)
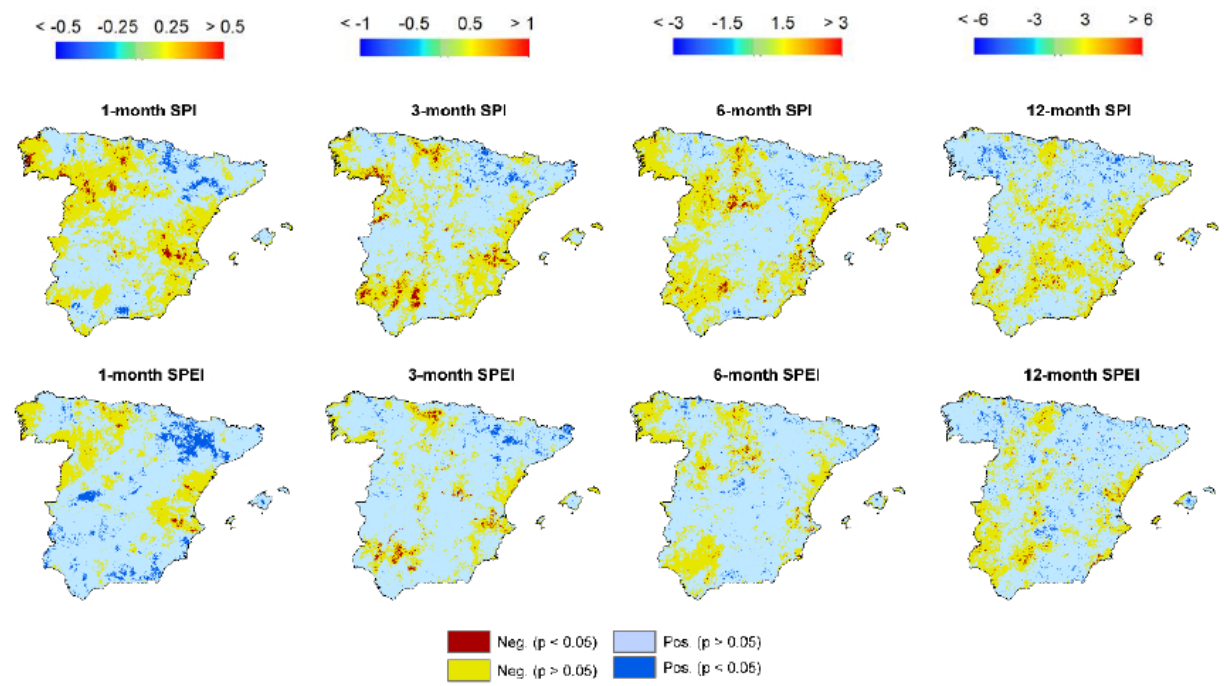

Figure 11: a) Spatial distribution of the magnitude of change (weeks per decade) in drought duration between the years 1961 and 2014, and the b) Sign and significance of the trends. 
(a)
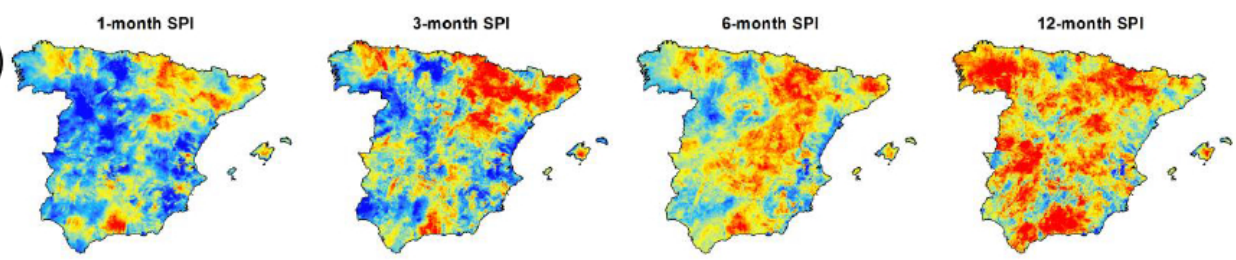

1-month SPEI
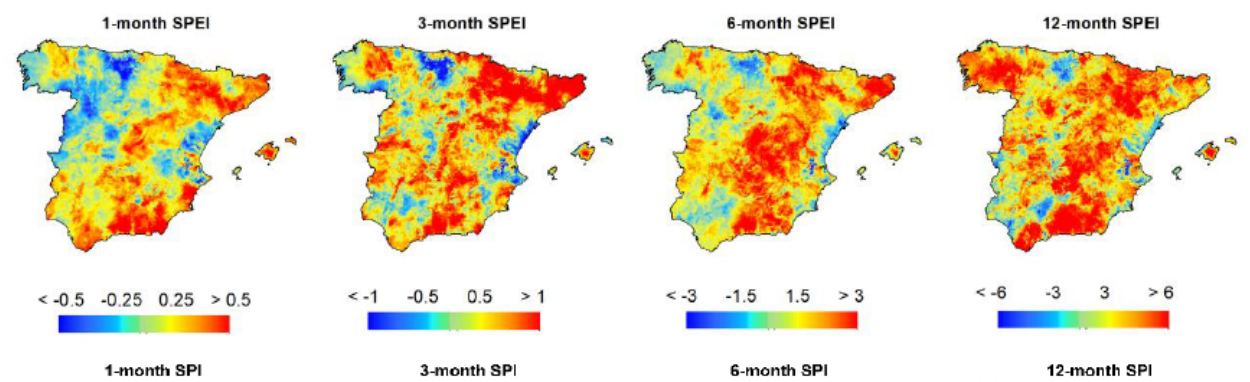

(b)
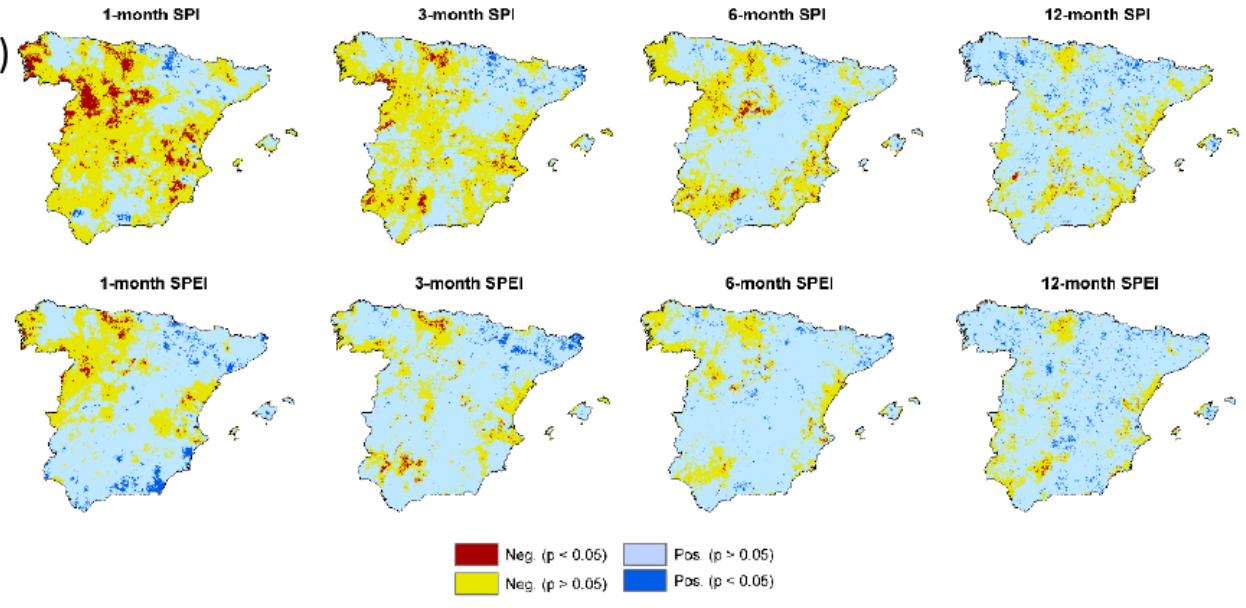

Figure 12: Spatial distribution of the differences of magnitude of change (z units) in drought magnitude between the years 1961 and 2014, and the b) sign and significance of the trends. 

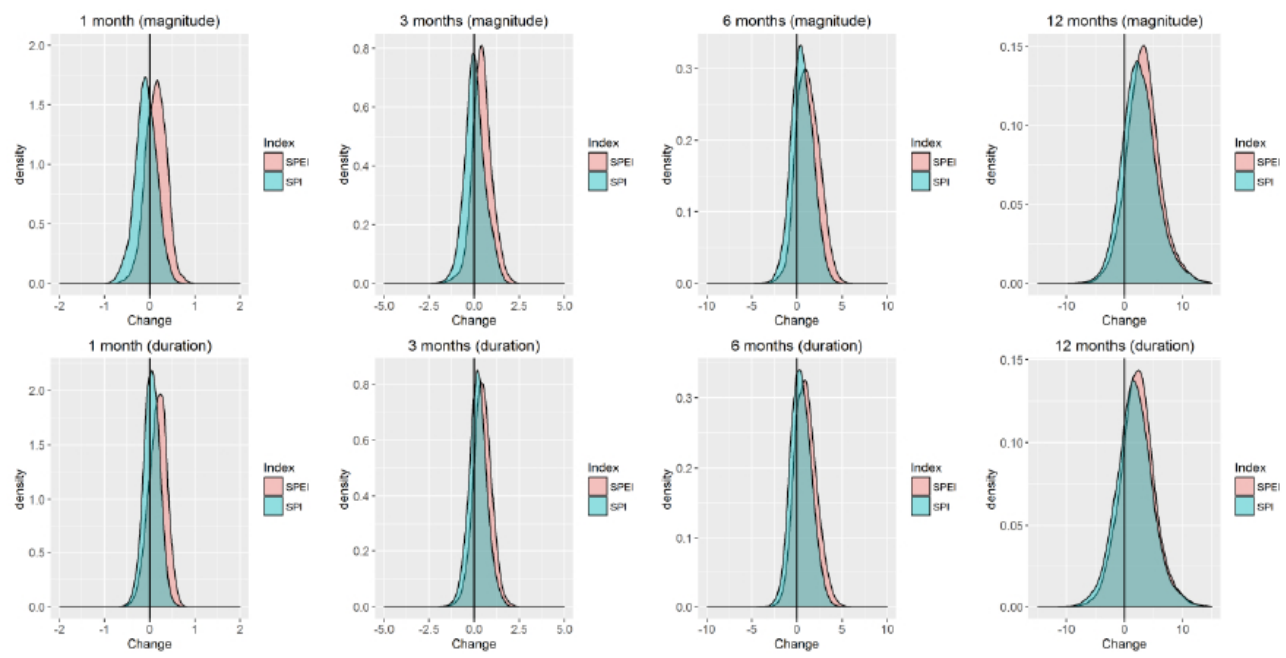

Figure 13: Density plots showing differences in drought duration and magnitude obtained with the SPI and SPEI. 

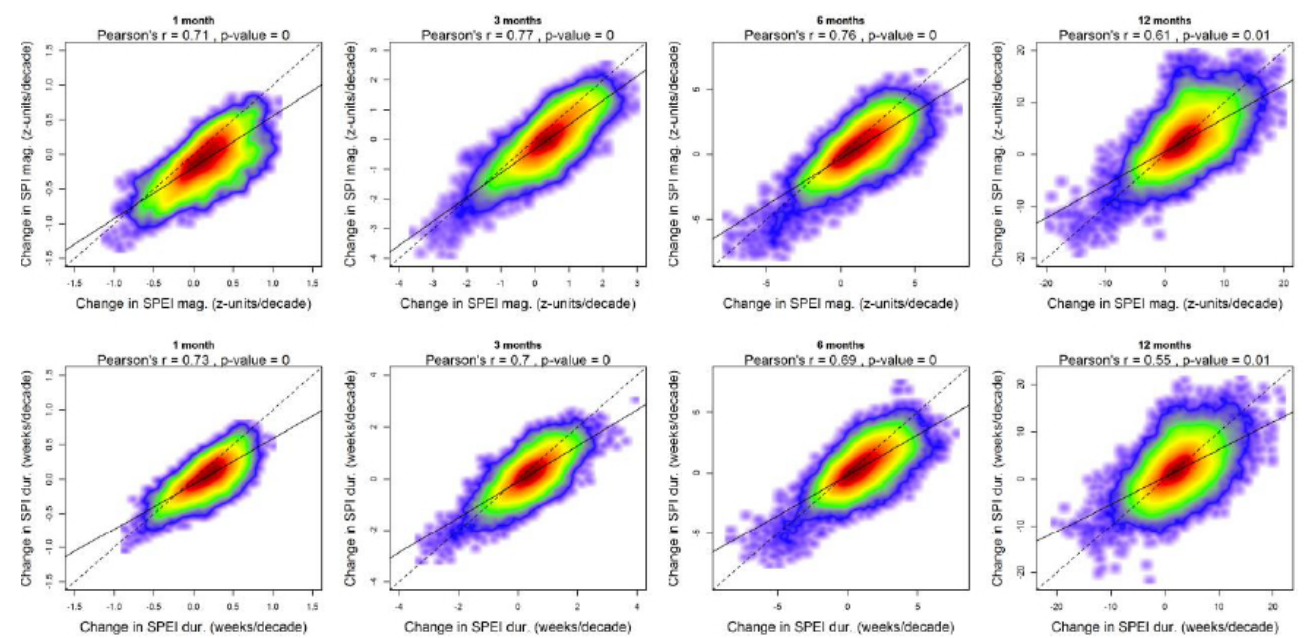

Figure 14: Scatterplots showing the relationships between differences in the magnitude (upper panels) and duration (lower panels) of drought events between the years 1961 and 2014, as derived from the SPEI against SPI. 
Table 1: Magnitude of change and trend significance of annual values of spatiallyaveraged magnitude and duration of drought events considering the SPI and SPEI at 1, 3, 6 and 12 months timescales.

\begin{tabular}{|c|c|c|c|c|c|c|c|c|}
\cline { 2 - 9 } \multicolumn{1}{c|}{} & \multicolumn{8}{c|}{ Magnitude } \\
\cline { 2 - 9 } \multicolumn{1}{c|}{} & \multicolumn{2}{c|}{1 month } & \multicolumn{2}{c|}{3 months } & \multicolumn{2}{c|}{6 months } & \multicolumn{2}{c|}{12 months } \\
\cline { 2 - 10 } & $\begin{array}{c}\text { change } \\
10 \text { years }\end{array}$ & p-value & $\begin{array}{c}\text { change } \\
10 \text { years }\end{array}$ & p-value & $\begin{array}{c}\text { change } \\
10 \text { years }\end{array}$ & p-value & $\begin{array}{c}\text { change } \\
10 \text { years }\end{array}$ & p-value \\
\hline SPI & $-0,059$ & 0,36 & $-0,27$ & 0,16 & 2,053 & 0,1 & 8,203 & 0,17 \\
\hline SPEI & 0,052 & 0,92 & 0,402 & 0,93 & 1,22 & 0,44 & 4,673 & 0,85 \\
\hline & \multicolumn{8}{|c|}{ Duration } \\
\hline SPI & 0,068 & 0,77 & $-0,253$ & 0,17 & 1,897 & 0,15 & 6,512 & 0,32 \\
\hline SPEI & 0,073 & 0,94 & 0,325 & 0,83 & 0,616 & 0,58 & 2,749 & 1 \\
\hline
\end{tabular}


Table 2: Percentage of surface showing positive and negative trends in the duration and the magnitude of drought events.

\begin{tabular}{|c|c|c|c|c|c|c|c|c|c|c|c|c|c|c|c|c|}
\hline & \multicolumn{8}{|c|}{ SPI } & \multicolumn{8}{|c|}{ SPEI } \\
\hline & \multicolumn{4}{|c|}{ Magnitude } & \multicolumn{4}{|c|}{ Duration } & \multicolumn{4}{|c|}{ Magnitude } & \multicolumn{4}{|c|}{ Duration } \\
\hline & $\begin{array}{c}1- \\
\text { month }\end{array}$ & $\begin{array}{c}\text { 3- } \\
\text { month } \\
s\end{array}$ & $\begin{array}{c}6- \\
\text { month } \\
s\end{array}$ & $\begin{array}{c}12- \\
\text { mont } \\
\text { hs }\end{array}$ & $\begin{array}{c}1- \\
\text { month }\end{array}$ & $\begin{array}{c}\text { 3- } \\
\text { month } \\
s\end{array}$ & $\begin{array}{c}6- \\
\text { mont } \\
\text { hs }\end{array}$ & $\begin{array}{c}12- \\
\text { mont } \\
\text { hs }\end{array}$ & $\begin{array}{c}1- \\
\text { mont } \\
h\end{array}$ & $\begin{array}{c}\text { 3- } \\
\text { month } \\
s\end{array}$ & $\begin{array}{c}6- \\
\text { month } \\
s\end{array}$ & $\begin{array}{c}12- \\
\text { month } \\
s\end{array}$ & $\begin{array}{c}1- \\
\text { month }\end{array}$ & $\begin{array}{c}\text { 3- } \\
\text { mont } \\
\text { hs }\end{array}$ & $\begin{array}{c}6- \\
\text { month } \\
s\end{array}$ & $\begin{array}{c}12- \\
\text { mont } \\
\text { hs }\end{array}$ \\
\hline $\begin{array}{l}\text { Negative } \\
(p<0.1)\end{array}$ & 14.61 & 6.01 & 4.76 & 2.25 & 3.94 & 5.06 & 4.38 & 2.47 & 3.63 & 2.91 & 1.45 & 1.56 & 1.10 & 3.07 & 1.74 & 2.09 \\
\hline $\begin{array}{l}\text { Negative } \\
(p>0.1)\end{array}$ & 49.93 & 43.26 & 28.25 & 16.42 & 36.73 & 28.38 & 32.26 & 25.70 & 24.27 & 16.41 & 15.46 & 10.40 & 18.23 & 14.49 & 20.35 & 19.62 \\
\hline $\begin{array}{l}\text { Positive ( } p \\
>0.1 \text { ) }\end{array}$ & 33.09 & 47.85 & 64.26 & 75.23 & 53.96 & 62.85 & 60.38 & 66.05 & 64.24 & 76.30 & 79.39 & 81.04 & 67.44 & 78.10 & 74.29 & 72.10 \\
\hline $\begin{array}{l}\text { Positive ( } p \\
<0.1 \text { ) }\end{array}$ & 2.37 & 2.88 & 2.73 & 6.10 & 5.37 & 3.71 & 2.98 & 5.78 & 7.86 & 4.37 & 3.70 & 7.00 & 13.23 & 4.33 & 3.63 & 6.19 \\
\hline
\end{tabular}
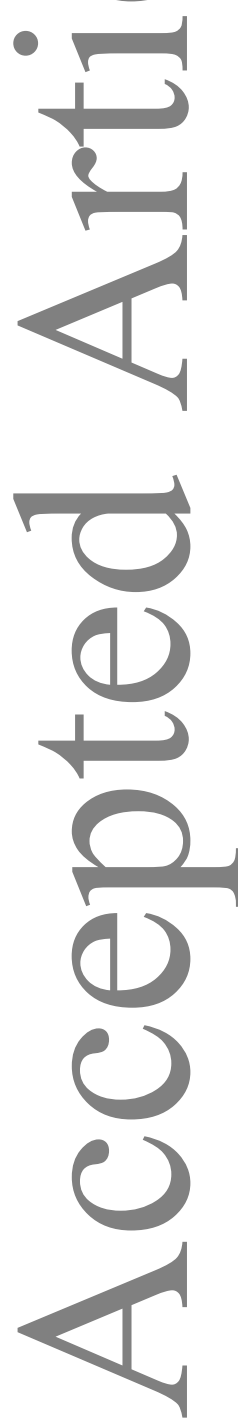